\title{
MATERIAIS E DESIGN: Compósito de moscovita e vidro
}

\author{
Danieli Maehler Nejeliski \\ Universidade Federal do Rio Grande do Sul - UFRGS \\ danielinejeliski@yahoo.com.br \\ Felipe Foerstnow Szczepaniak \\ Universidade Federal do Rio Grande do Sul - UFRGS \\ foerspak@gmail.com \\ Lauren da Cunha Duarte \\ Universidade Federal do Rio Grande do Sul - UFRGS \\ lauren.duarte@ufrgs.br \\ Liane Roldo \\ Universidade Federal do Rio Grande do Sul - UFRGS \\ liane.roldo@ufrgs.br
}

\begin{abstract}
Resumo: A moscovita possui características estéticas como brilho, translucidez, e nuances de cores que variam entre o amarelo, castanho, verde e vermelho. Entretanto, a sua estrutura física, disposta em lâminas extremamente finas ou escamas, limita a sua aplicação. $O$ procedimento experimental tem como objetivo a fusão de vidro com lamelas de moscovita, para verificar se as características estéticas desta mica se mantêm na matriz do vidro, potencializando a utilização do material resultante no design de produtos. Foram obtidas três amostras, com 10, 30 e $50 \%$ de massa de moscovita, com o vidro fundido em temperaturas distintas. A caracterização das amostras foi feita através de análise macroscópica e microscópica, sendo a última através de microscopia eletrônica de varredura (MEV) e difratometria de raios X. As amostras resultantes possuem características distintas de cor e brilho, bem como de dureza.
\end{abstract}

Palavras-chave: design de produto, compósito, moscovita, vidro.

Abstract: The muscovite has aesthetic characteristics as luster, translucency, and shades of colors ranging from yellow, brown, green and red. However, its physical structure, arranged in extremely thin flakes or blades, limits its application. The experimental procedure is aimed at fusing glass lamellae muscovite, to verify that the aesthetic features of this mica 
remaining in the glass matrix, increasing the use of the resulting material in product design. Three samples with 10, 30 and $50 \%$ by weight of muscovite were obtained with molten glass at different temperatures. The characterization of the samples was done by macroscopic and microscopic analysis, the latter by scanning diffraction electron microscopy and $X$-ray diffraction. The resulting samples showed different characteristics of color and brightness, as well as hardness.

Keywords: product design, composite, muscovite, glass.

\section{INTRODUÇÃO}

Os materiais são fundamentais no processo de design na medida em que materializam as ideias e viabilizam a concretização do projeto. É através deles que as características funcionais e estéticas se manifestam e o usuário interage com o produto. Para Ashby e Johnson (2010, p. 55) "materiais são a matéria de que é feito o design de produto". Tanto que a ciência dos materiais é uma área em constante inovação, a tal ponto que novos materiais são desenvolvidos exatamente com as propriedades que se deseja para um determinado fim, com tamanha variedade de opções que se estima termos disponíveis cerca de 100.000 materiais diferentes (ASHBY \& JOHNSON, 2010).

Os compósitos ilustram o avanço no desenvolvimento de novos materiais. Em essência, são uma combinação de dois ou mais materiais com propriedades distintas, de modo que o produto resultante possui propriedades superiores a qualquer um deles isolados. A fibra de vidro é um exemplo clássico, onde a resistência das fibras de vidro de pequeno diâmetro é combinada com a ductilidade da matriz polimérica (SHACKELFORD, 2008). A possibilidade de utilização de materiais tão específicos no design expande a capacidade criativa do projetista corroborando para o surgimento de produtos mais inovadores. Os compósitos permitem também o aproveitamento de materiais que isolados, têm sua aplicação limitada, como é o caso da moscovita.

A moscovita, uma variedade de mica, é um mineral formador de rocha comum e abundante, sendo característico de granitos e pegmatitos graníticos. Possui características estéticas acentuadas, como brilho e tonalidades de cores variadas. Seu brilho pode ser classificado como sendo vítreo a sedoso ou nacarado. Transparente e incolor nas folhas delgadas, translúcida em blocos mais espessos, com matizes claros do amarelo, castanho, verde e vermelho. Com relação às propriedades físicas, possui clivagem perfeita, permitindo o desdobramento do material em folhas/lamelas muitíssimo finas, com lâminas muito flexíveis e elásticas (KLEIN \& DUTROW, 2012). Justamente essas características físicas específicas da moscovita que acabam por limitar a sua aplicação.

A utilização industrial da moscovita é bastante restrita. Devido a sua elevada propriedade dielétrica e resistência ao calor, placas de moscovita são utilizadas como material isolante na produção de aparelhagem elétrica. Pequenas peças utilizadas para isolamento elétrico são construídas com folhas delgadas de mica cimentadas entre si, podendo ser prensadas na forma desejada antes que o cimento endureça. A moscovita é usada como material transparente em portas de fornos e lanternas, e os resíduos são utilizados em papeis de parede para lhes dar brilho reluzente, misturados com óleos 
para fins de lubrificação, no isolamento do calor e na fabricação de material combustível (KLEIN \& DUTROW, 2012).

As propriedades estéticas da mica são limitadamente exploradas na produção de pigmentos perolizados, tipo de pigmento que possui brilho perolado devido ao ângulo de transmissão da luz através das camadas transparentes dos óxidos metálicos sobre substratos minerais com diferentes índices de refração, sendo o pigmento de mica o mais utilizado por produzir um efeito único em função de sua transparência. Os pigmentos perolizados são largamente utilizados na indústria, na produção de papel moeda, como material decorativo na indústria de cosméticos, embalagens plásticas, indústria automotiva e em cerâmicas de revestimento, onde o efeito metálico em várias tonalidades é extremamente valorizado (CAVALCANTE et al, 2006).

Uma possibilidade de explorar o potencial estético da moscovita seria na constituição de um compósito, onde o material utilizado como matriz ressaltasse as características estéticas do mineral, ao mesmo tempo em que fornecesse a resistência e estabilidade que a moscovita não possui. O vidro é um material muito utilizado como matriz para compósitos com metais e minerais em função de suas características intrínsecas de facilidade de coloração e brilho, de modo que ressalta as características do material com o qual é fundido. Tais características transformaram o vidro no material base mais utilizado na produção de gemas artificiais, pois consegue alcançar toda a beleza necessária que a caracterização de uma gema requer (KLEIN \& DUTROW, 2012).

Compósitos de moscovita e vidro já são uma realidade, sendo muito utilizados em restaurações dentárias. O material resultante é biocompatível, possui tenacidade à fratura superior quando comparado ao vidro puro em função da deflexão de trincas proporcionada pela moscovita, o que confere ao material excelente usinabilidade. 0 compósito é gerado a partir da sinterização dos materiais, cuidadosamente selecionados (MORAES, OGASAWARA E PEREIRA, 2010). Nesse caso, são as propriedades físicas da moscovita que são exploradas, de modo que as suas características estéticas não são visíveis no produto resultante.

$O$ procedimento experimental realizado nesta pesquisa tem como objetivo a combinação de moscovita com vidro para a geração de um compósito, a fim de verificar se serão mantidas as características estéticas da mica na matriz vítrea, potencializando o uso do material no design de produtos. Foram obtidas três amostras, com 10, 30 e $50 \%$ de massa de moscovita, fundidas em temperaturas distintas. A caracterização das amostras foi feita em escala macroscópica e microscópica. A primeira escala de observação refere-se à observação das propriedades estéticas, facilmente identificáveis, como a cor, o brilho e a textura. Já as análises microscópicas foram realizadas por microscopia eletrônica de varredura (MEV) e por espectroscopia de raios-X por dispersão em energia (EDS), e também por difratometria de raios- $X$, ambas as técnicas são muito utilizadas na caracterização de materiais minerais (VASCONCELLOS \& HINRICHS, 2010).

\section{DESENVOLVIMENTO}

\subsection{Materiais e Métodos}

Todo o processo de fusão dos materiais, desde a transformação em pó até a fundição propriamente dita, bem como a difratometria de raios- $X$, foi realizado nas dependências do LACER - Laboratório de Materiais Cerâmicos - e as análises 
macroscópicas e microscópicas no LdSM -Laboratório de Design e Seleção de Materiais - ambos localizados no prédio da Engenharia Nova da Universidade Federal do Rio Grande do Sul - UFRGS.

A amostra de moscovita utilizada foi coletada em pegmatito da localidade de Chapéu Duro, em Minas Gerais. A composição da amostra de moscovita utilizada no procedimento experimental foi identificada através de análise química por ICP-MS, realizada no Laboratório de Geoquímica Ambiental da UFOP, consistiu na leitura de 24 elementos químicos presentes na amostra e a identificação desta mica como moscovita (DUARTE, 2004).

O resultado da análise foi dividido em duas etapas: a primeira, apresentada na Tabela 1, relaciona os óxidos e a segunda elenca os elementos químicos predominantes. Com relação aos óxidos, a especificação está relacionada a uma porcentagem em massa total de $47,6 \%$, sendo 0 restante composto predominantemente por $\mathrm{SiO}_{2}$. A alumina $\left(\mathrm{Al}_{2} \mathrm{O}_{3}\right)$ é o mais representativo, com porcentagem muito superior aos demais. $\mathrm{O}$ óxido de potássio $\left(\mathrm{K}_{2} \mathrm{O}\right)$ juntamente com o óxido de ferro $\left(\mathrm{Fe}_{2} \mathrm{O}_{3}\right)$ também aparece em quantidade significativa.

Tabela 1: Relação dos óxidos presentes na amostra de moscovita analisada

\begin{tabular}{ll}
\hline Óxidos & Massa (\%) \\
\hline $\mathrm{Al}_{2} \mathrm{O}_{3}$ & 32,4 \\
\hline $\mathrm{Fe}_{2} \mathrm{O}_{3}$ & 4,3 \\
\hline $\mathrm{CaO}$ & 0,0 \\
\hline $\mathrm{MgO}$ & 0,7 \\
\hline $\mathrm{K}_{2} \mathrm{O}$ & 9,2 \\
\hline $\mathrm{Na}_{2} \mathrm{O}$ & 0,5 \\
\hline $\mathrm{TiO}_{2}$ & 0,4 \\
\hline $\mathrm{MnO}$ & 0,1 \\
\hline
\end{tabular}

Fonte: Adaptada de Duarte (2004).

Com relação aos demais elementos químicos, uma ampla variedade foi identificada, entretanto os mais representativos, com relação à proporção, foram o lítio (Li) e o zinco (Zn). Elementos como o vanádio (V), berílio (Be) e escândio (Sc) aparecem em quantidades menos representativas.

A amostra de vidro utilizada foi cedida pelo LACER, sendo este material já desagregado, já tendo sido moído a seco por moinho de bolas e posteriormente, peneirado em peneira de malha 300 mesh, estando pronto para a fundição. A partir de análise química qualitativa e semi-quantitativa feita por espectrômetro de raios-X por dispersão de energia (EDS), acoplado ao MEV, observou-se na composição básica do vidro branco $\mathrm{SiO}_{2}, \mathrm{Na}_{2} \mathrm{O}, \mathrm{CaO}$ e $\mathrm{Al}_{2} \mathrm{O}_{3}$, e uma quantidade representativa de ferro (Fe), cerca de $14 \%$ do total.

A amostra de moscovita foi recebida em sua forma bruta, caracteristicamente laminada em folhas. Para prepará-la para o compósito a primeira etapa consistiu na cominuição desta em pó. Portanto, realizou-se primeiramente o seu desfolhamento a mão e a sua trituração com tesoura, e em seguida, a sua moagem a seco com uso de 
pistilo e gral de porcelana. O material foi peneirado a 300 mesh. Com ambos os materiais pulverizados, foram preparadas as amostras para fusão.

Três concentrações distintas foram utilizadas para o procedimento experimental. A proporção da concentração foi calculada com base no peso em massa de cada material, obtido a partir do uso de uma balança de precisão. Após a pesagem, os materiais em pó foram misturados no gral, já na proporção correta de cada amostra, e então foram vertidos em cadinhos de alumina, cada um com $1 \mathrm{ml}$ de capacidade. As amostras foram levadas para a fundição em um forno elétrico Sanchis ${ }^{\circledR}$, o qual não possibilita a retirada de oxigênio de seu interior.

A Amostra 1 teve concentração de $50 \%$ de massa de vidro branco e $50 \%$ de massa de moscovita, a primeira a ser testada, levada ao forno em quatro temperaturas de patamar diferentes, $650^{\circ} \mathrm{C}, 750^{\circ} \mathrm{C}, 850^{\circ} \mathrm{C}$ e $1100^{\circ} \mathrm{C}$, ambas com taxa de aquecimento de $10^{\circ} \mathrm{C} / \mathrm{min}$, permanecendo 5 minutos na temperatura máxima, e com resfriamento lento. A concentração da Amostra 2 foi de $70 \%$ vidro e $30 \%$ moscovita e da Amostra 3 foi de $90 \%$ vidro para 10\% moscovita. As amostras 2 e 3 foram levadas ao forno juntas, submetidas a uma temperatura de patamar de $1000^{\circ} \mathrm{C}$, com taxa de aquecimento de $10^{\circ} \mathrm{C} / \mathrm{min}$, permanecendo 5 minutos na temperatura máxima, e resfriamento lento.

Após o procedimento de fusão, as amostras foram avaliadas por meio de análise macroscópica e microscópica. Macroscopicamente podemos identificar características gerais do material, bem como obter informações básicas como a cor, brilho, textura e dureza. Já a análise microscópica caracteriza o material conforme a sua microestrutura, detalhando os elementos e sua organização estrutural. Para a microscopia eletrônica de varredura (MEV), foi utilizado um equipamento da marca Hitachi $^{\circledR}$ modelo TM 3000, localizado no LDSM, UFRGS. Foram obtidas imagens eletrônicas do tipo BSE (backscattered electron), com aceleração do feixe de elétrons de $15 \mathrm{KeV}$, e com aumentos de até 1.000 vezes. A difratrometria de raios- $X$, foi realizada com o equipamento Philips X'pert MPD, sendo os parâmetros de intervalo de $5-75^{\circ} 2 \theta$. Os dados foram analisados utilizando o programa $X^{\prime}$ pert HighScore ${ }^{\circledR}$.

\subsection{Resultados}

O processo de moagem da moscovita foi lento, tendo em vista a dificuldade de pulverizar manualmente o mineral, em função da sua disposição em lâminas e da sua clivagem. Deste modo, optou-se por peneirar o farelo com peneira 300 mesh, com isso, foram obtidos fragmentos de moscovita com dimensões maiores que os do vidro utilizado.

Nos três primeiros ensaios, realizados com a Amostra 1 ( $50 \%$ mica) com o forno com temperaturas de $650^{\circ} \mathrm{C}, 750^{\circ} \mathrm{C}$ e $850^{\circ} \mathrm{C}$, os materiais não fundiram. Na quarta tentativa, com temperatura em $1100^{\circ} \mathrm{C}$, o vidro fundiu cimentando os cristais de moscovita. Os exemplares da Amostra 2 (30\% mica) e da Amostra 3 (10\% mica) fundiram parcialmente na primeira tentativa, com temperatura de $1000^{\circ} \mathrm{C}$. Na Amostra 2 o vidro não fundiu totalmente, não havendo a cimentação que ocorreu na Amostra 1 , de modo que o material resultante ficou friável. Já na Amostra 3 o vidro fundiu, e em função de sua grande concentração na mistura (90\%), a cimentação foi mais efetiva, e o material ficou visivelmente mais resistente que as demais amostras (Fig. 1). 


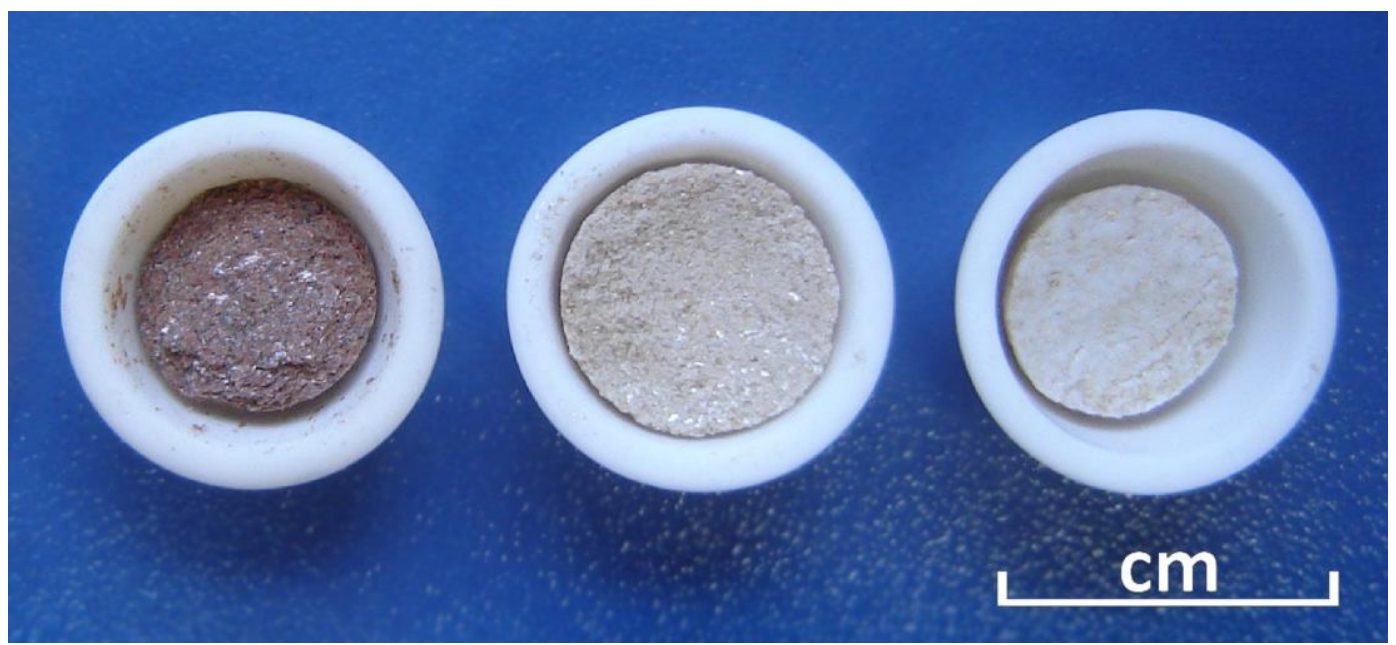

Figura 1 - Da esquerda para a direita: Amostra 1, Amostra 2 e Amostra 3. Elaborado pelo autor, com base na pesquisa realizada.

Os resultados das análises macroscópicas caracterizam as amostras quanto ás suas propriedades de cimentação, brilho e cor (Quadro 1). Na amostra 1, observou-se a oxidação do material em função da tonalidade avermelhada resultante, reação entre o óxido de ferro presente tanto na moscovita quanto no vidro. A amostra obtida possui coloração homogênea de cobre, com alto brilho emitido pelos cristais da moscovita que não foram fundidos. O vidro visivelmente fundiu e cimentou a mica, mas a cimentação não foi eficiente, deixando a amostra porosa e quebradiça.

Quadro 1 - Resultados da análise macroscópica das amostras.

\begin{tabular}{|l|l|l|l|l|l|}
\hline $\begin{array}{l}\text { Número da } \\
\text { amostra }\end{array}$ & $\begin{array}{l}\text { Concentração de } \\
\text { moscovita (\%) }\end{array}$ & $\begin{array}{l}\text { Temperatura } \\
\text { de fusão }\left({ }^{\circ} \mathbf{C}\right)\end{array}$ & Cimentação & Brilho & Cor \\
\hline $\mathbf{1}$ & 50 & 1100 & Friável & Alto & Cobre \\
\hline $\mathbf{2}$ & 30 & 1000 & Friável & Alto & Nude \\
\hline $\mathbf{3}$ & 10 & 1000 & Compacta & Baixo & $\begin{array}{l}\text { Nude } \\
\text { claro }\end{array}$ \\
\hline
\end{tabular}

Fonte: Elaborado pelo autor, com base na pesquisa realizada.

A Amostra 3 não apresentou sinais de oxidação, de modo que a sua coloração final foi ainda mais clara que a da Amostra 2, possivelmente pela maior concentração de vidro na mistura. Apresentou coloração geral esbranquiçada, com esparsos cristais dourados de mica, com brilho consideravelmente inferior às amostras anteriores. 0 vidro formou um cimento espesso e resistente, em função de sua proporção em relação à moscovita, de modo que a amostra obtida possui consistência compactada, visivelmente mais resistente que as demais amostras.

Nas imagens geradas a partir da microscopia eletrônica de varredura (MEV), podem-se observar as lâminas da moscovita nas três amostras (Fig. 2). O vidro, ao ser observado ao MEV, é um material homogêneo e percebe-se a presença de poros (Fig. 2a). Para a Amostra 1, com $50 \%$ de moscovita, pode-se verificar que não houve a fusão e coesão entre os dois materiais, pois os materiais estão visivelmente separados (Fig. 2b) o que justifica o material ser friável. 

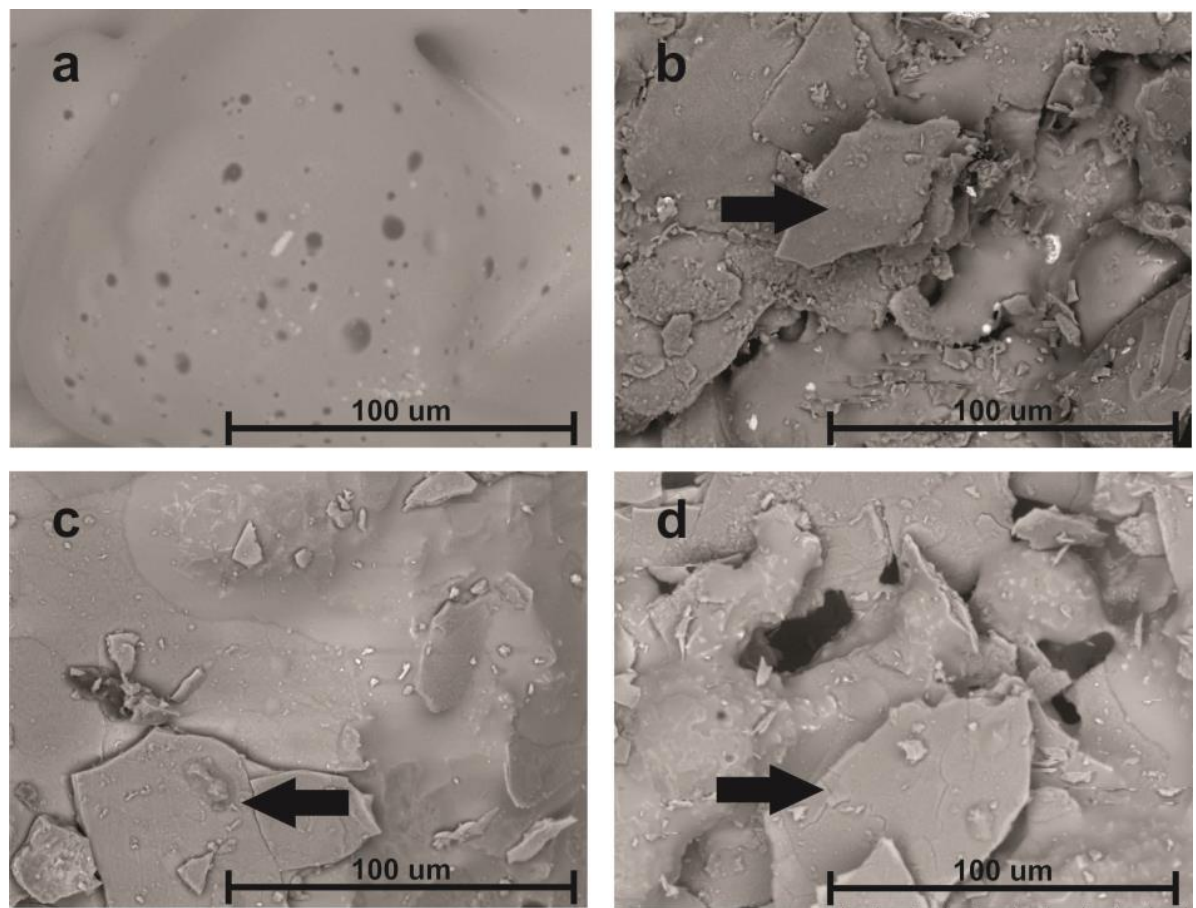

Figura 2 - Imagens eletrônica do tipo BSE, onde em a) vidro puro, b) Amostra 1, c)

Amostra 2 e d) Amostra 3, onde as setas indicam as lamelas de moscovita.

Para a Amostra 2, com 30\% de moscovita, percebe-se uma maior coesão entre as lâminas de mica e a matriz vítrea (Fig. $2 \mathrm{c}$ ), bem como uma concentração menor do mineral, com relação à Amostra 1. Para a Amostra 3, com apenas $10 \%$ de mica, podese observar que há uma maior coesão/cimentação entre as lamelas de moscovita e o vidro fundido (Fig. 2d), havendo uma maior integração dos materiais, justificando o fato desta amostra ser a menos quebradiça das três.

Quanto aos dados dos EDS obtidos, os elementos identificados nas Amostras 1, 2 e 3 foram muito similares, com variações com relação à porcentagem. 0 segundo elemento mais representativo é o silício (Si), em torno de $25 \%$ do total. Os demais elementos presentes nas amostras são o sódio ( $\mathrm{Na}$ ), alumínio (Al), potássio (K), cálcio (Ca) e ferro (Fe), em quantidades menos representativas.

Com relação aos resultados da DRX o difratograma obtido para a moscovita identifica picos bem definidos e a organização cristalina característica deste material, responsável pela sua clivagem perfeita e resistência ao calor, dentre outras propriedades. O difratograma foi analisado no programa X'pert HighScore ${ }^{\circledR}$, onde a partir da restrição dos elementos $\mathrm{O}, \mathrm{Al}, \mathrm{Si}, \mathrm{Fe}, \mathrm{K}$ e $\mathrm{Li}$, conseguiu-se a definição do composto que melhor se relacionou com os picos em questão, que foi a própria moscovita - composição química $\mathrm{KAl}(\mathrm{FeLi})\left(\mathrm{Si}_{3} \mathrm{Al}\right) \mathrm{O}_{10} \mathrm{~F}_{2}$. A figura 3 apresenta os principais picos de identificação do mineral. 


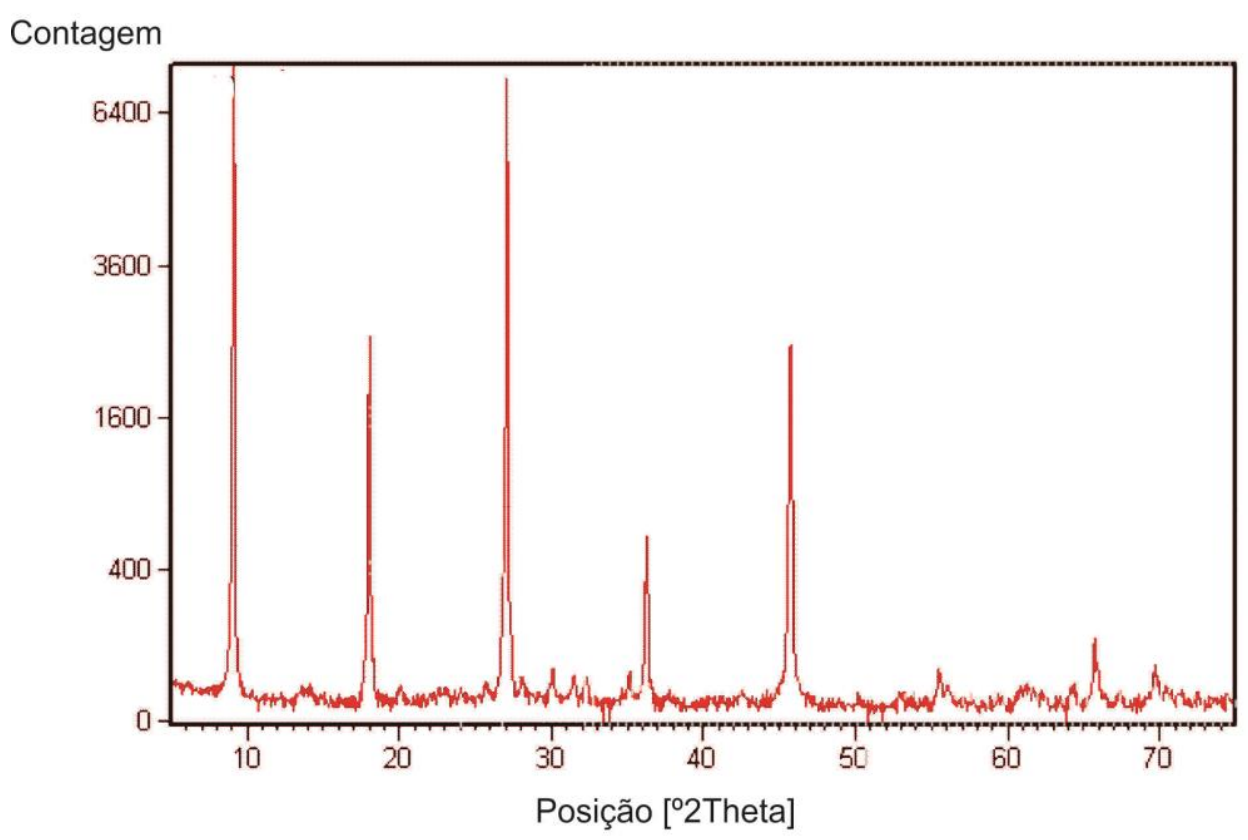

Figura 3 - Difratograma da moscovita.

A difratometria de raios- $X$ também auxiliou na caracterização das amostras do compósito (Fig. 4) das amostras 1 e 2. Para estes resultados o material encaminhado para a análise correspondente à amostra 3 não foi suficiente.

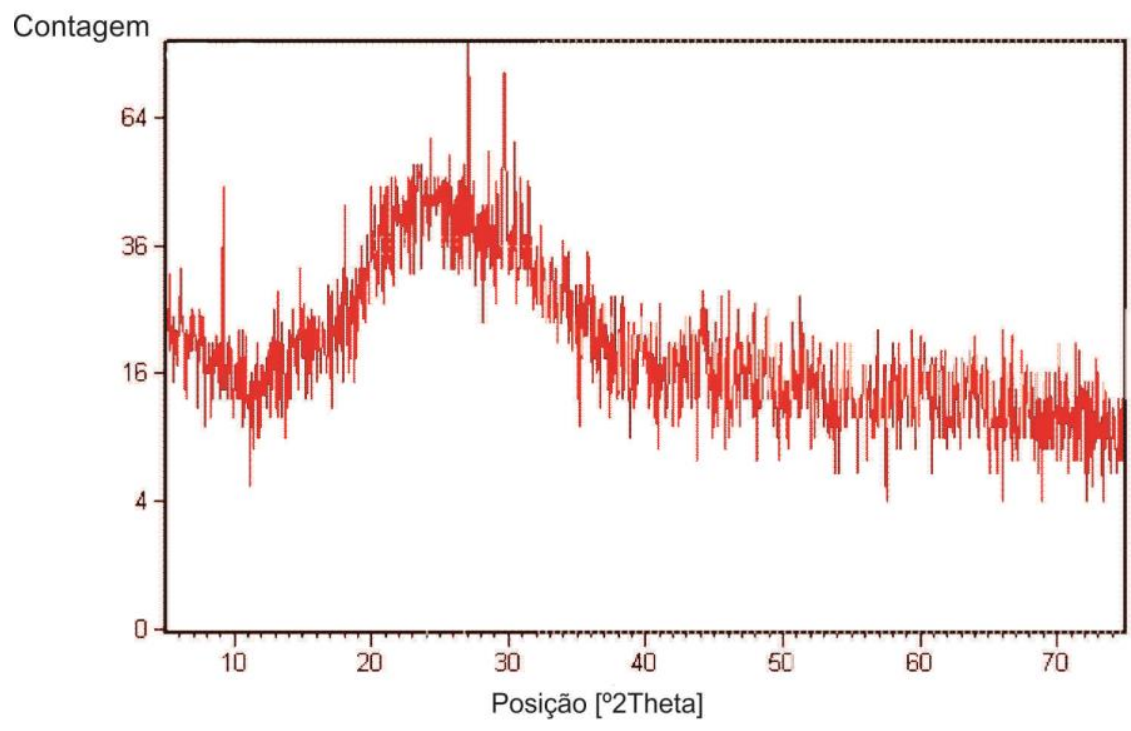

a 

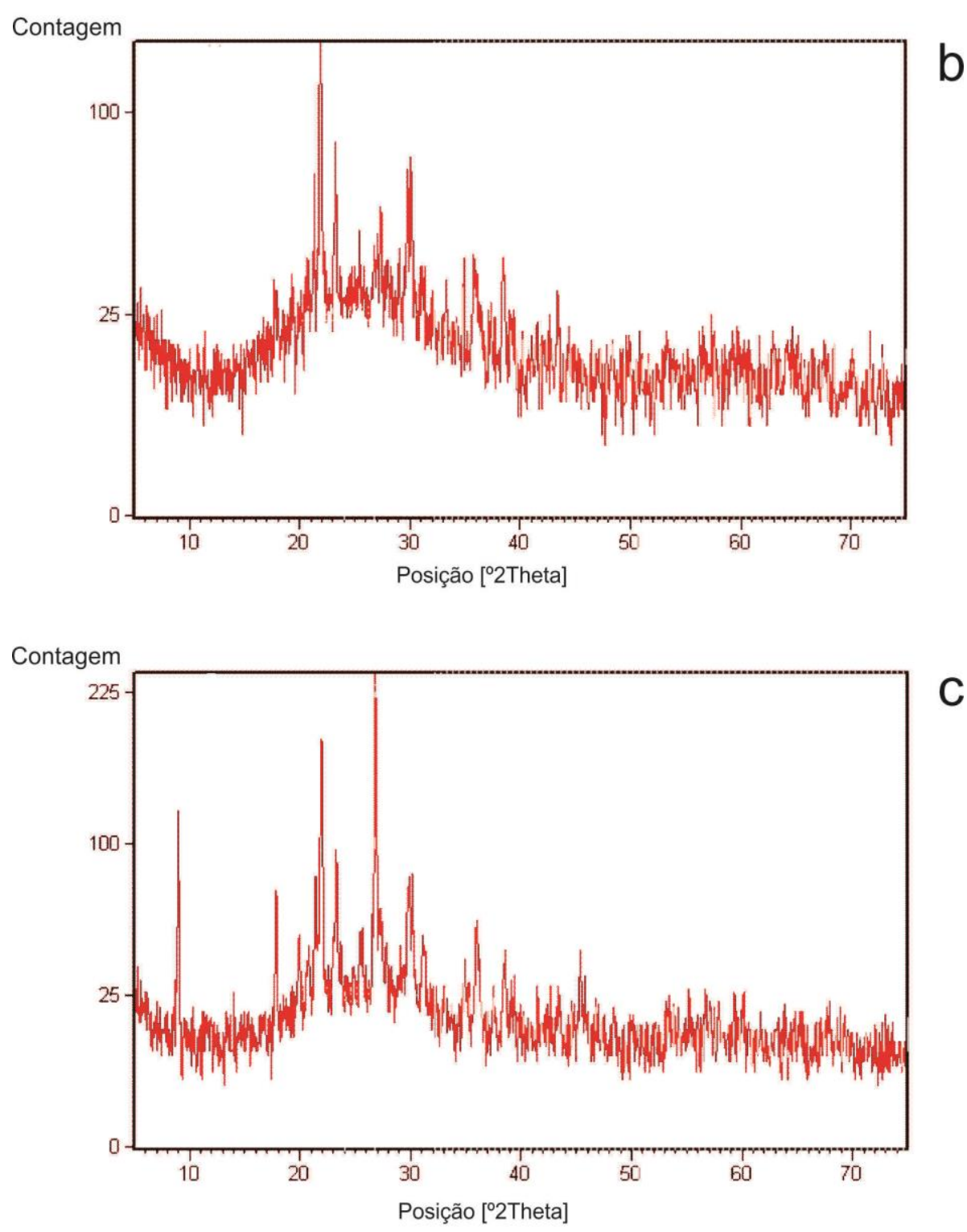

C

Figura 4 - Padrões de difratometria de raios $X$ para as amostras com: a) $100 \%$ vidro;

b) $\mathbf{7 0} \%$ vidro $+\mathbf{3 0} \%$ moscovita, c) $\mathbf{5 0 \%}$ vidro $+\mathbf{5 0} \%$ moscovita.

No difratograma do vidro branco, pode-se observar um padrão característico dos materiais amorfos, onde não podem ser identificados picos (Fig. 4a). Nos difratogramas das Amostras 1 (Fig. 4b) e 2 (Fig. 4c) também pode-se observar o mesmo padrão de material amorfo do vidro, porém os picos característicos da moscovita estão presentes, indicando que não houve a fusão deste material.

\section{CONCLUSÃO}

As amostras resultantes possuem variação de cor e tonalidade, mantendo o brilho característico dos cristais de moscovita, fatores relevantes para aplicação em design de produto. Possuem ainda variação de coesão devido às diferentes concentrações das fases e às temperaturas de fusão a que foram submetidas. Novos parâmetros podem ser ensaiados, buscando a resistência deste material para ser utilizado conforme as exigências da aplicação em diferentes produtos. 
Em virtude da fusão parcial das amostras, principalmente a porção vítrea, e não fusão da moscovita, as amostras com maior conteúdo de mica ficaram frágeis e quebradiças, e por isto não se puderam determinar as propriedades mecânicas destas para futuras aplicações em design e para determinar os processos de fabricação pelos quais poderá passar. Como não se chegou ao ponto de fusão da moscovita, não se sabe se o efeito da variação da tonalidade conforme a concentração e do brilho dos cristais se manteria no momento que os dois materiais fundissem e formassem e fossem sinterizados.

O procedimento experimental mostrou potencial do material para aplicação em design de produto, sendo o resultado mais satisfatório (Amostra 3) um material com as características de resistência e estabilidade do vidro, aliadas às qualidades estéticas da moscovita, poderia ter o potencial explorado em distintos produtos. Entretanto, para se chegar a informações conclusivas, mostram-se necessários novos testes e análises.

\section{AGRADECIMENTOS}

Os autores agradecem o apoio financeiro do CNPq e da CAPES pelas bolsas de Mestrado e pelas bolsas de Produtividade em Pesquisa.

Ao LACER - Laboratório de Materiais Cerâmicos da UFRGS pela disponibilidade e auxílio na pesquisa realizada.

\section{REFERÊNCIAS}

ASHBY, M. F.; JOHNSON, K. Materials and design: the art and science of material selection in product design. Amsterdam: Elsevier/Butterworth-Heinemann, 2010.

CAVALCANTE, P. M. T. et al. Síntese de pigmento perolizado micáceo pelos métodos de coprecipitação e pechini. Anais do $50^{\circ}$ Congresso Brasileiro de Cerâmica. Blumenau, SC, 2006.

DUARTE, L. C. Características geoquímicas de pegmatitos portadores e não portadores de minerais-gemas. Monografia. Curso de Especialização em Gemologia. Programa de Pós-Graduação em Evolução Crustal e Recursos Naturais, DEGEO/EM/UFOP. Ouro Preto, MG, 2004.

KLEIN, C.; DUTROW, B. Manual de ciência dos minerais. Tradução e revisão técnica: Rualdo Menegat. 23 ed. Porto Alegre: Bookman, 2012.

MORAES, E. E. S.; OGASAWARA, T.; Pereira L. C. Desenvolvimento de compósito micamuscovita para cerâmicas dentárias. Painel PEMM, COPPE, UFRJ, 2010.

SHACKELFORD, J. F. Introdução à ciência dos materiais para engenheiros. São Paulo: Pearson Prentice Hall, 2008.

VASCONCELLOS, M. A. Z., HINRICHS, R. Microanálise na caracterização de gemas e joias. In: Tecnologias para o setor de gemas, joias e mineração. Organizadores: Léo Afraneo Hartmann; Juliano Tonezer da Silva. Porto Alegre: IGEO/UFRGS, 2010. 